\title{
END-OF-LIFE TYRE RECYCLING: GOING BEYOND TO NEW CIRCULAR BUSINESS MODELS IN LATVIA
}

\author{
Inga Uvarova ${ }^{1,2}$, Dzintra Atstaja ${ }^{1,2}$, Viola Korpa ${ }^{3}$, Liga Avena ${ }^{3}$, Miks Erdmanis ${ }^{1}$ \\ ${ }^{1}$ BA School of Business and Finance, Latvia; ${ }^{2}$ Liepaja University, Latvia; \\ ${ }^{3}$ Riga Stradins University, Latvia \\ inga.uvarova@gmail.com,dzintra.atstaja@ba.lv, viola.korpa@gmail.com, \\ liga.avena.lv@gmail.com, miks.erdmanis@gmail.com
}

\begin{abstract}
The end-of-life tyre recycling industry in Latvia faces significant issues on a national level and on a micro business level. The aim of the research is the clarification of opportunities for new circular business models within the tyre recycling industry in Latvia. The main research methods are literature review, semistructured in-depth interviews, case studies, content analyses, and quantitative statistical analyses, qualitative and descriptive analyses, allowing providing integrative interdisciplinary assessment. In addition, design-thinking methods contributed to conclusions on future opportunities of new tyre recycling business models. The research shows that the system is insufficiently supervised, and it does not facilitate the development of new environmentally friendly technologies and circular business models. A large share of tyres ends up in waste landfills, are incinerated or illegally stored, whereas only a small number of them are recycled. The traditional tyre incineration methods are ineffective and create adverse effects on the environment. Tyre recycling companies in Latvia are not active in adoption of new technologies and business models. This justifies the topicality of the research problem. The research results reveal that globally new opportunities are being actively explored on how to produce higher added value products from materials obtained in the tyre recycling process. In Latvia, it is possible to develop new financially viable circular business models in tyre recycling industry, for instance, by producing tyre-derived aggregates for construction materials or pavement subbases. Besides the need for dynamic innovation capabilities of entrepreneurs, development of new business models in tyre recycling requires collaboration among various stakeholders. In addition, the government has a significant role in implementing the Green Public Procurement for the industries utilizing products gained as a result of tyre recycling.
\end{abstract}

Keywords: circular business models, tyre recycling, sustainable business.

\section{Introduction}

Although the tyre recycling in some extent is not so environmentally friendly process, it possesses less danger to the environment than storing these tyres in specifically designated areas or waste landfills, or even worst, illegally leaving them in the woods or elsewhere in nature. These issues now are important within the discourse of the circular economy (CE). In the last 5 to 10 years, the idea of the $\mathrm{CE}$ has been important within the agenda of European tyre manufacturers seeking and promoting innovative and sustainable solutions that ensure longer use of tyres and proper EOL waste recycling at the highest possible value and with less emission [1]. In addition, the European Commission with the European Green Deal highlights the increased importance of the recycling of EOL tyres [2].

The issues of tyre recycling in Latvia are now becoming more important for a number of reasons. There are very large stocks of end-of-life (EOL) tyres in Latvia. They are often stored in illegal storage facilities and accidentally burned. The tyre consumption continues to grow [3], but the number of recycled EOL tyres is not sufficient. According to last available statistical data, in 2017 in Latvia, just $38 \%$ of EOL tyres were recycled and $21 \%$ treated as the material for heating [4].

The CE conceives the business models that optimise resource flows and ensure closed-loop supply chains currently known as circular business models [5-7]. Although in previous decades recycling technologies have been applied and studied in various industries mainly from technical, mechanical or chemical perspectives [8-10], currently it is considered as one of the types of circular business models (CBMs) from the perspective of business model innovations in companies.

The aim of this research is the clarification of opportunities for new circular business models within the tyre recycling industry in Latvia. The research was performed in the following steps: 1) exploration of theoretical concepts, definitions and interpretations regarding the tyre recycling, circular business models and related terms; 2) conceptualisation and analyses of the existing tyre recycling situation in Latvia; 3) analyses of tyre recycling business models in Latvia; 4) descriptive 
analyses of opportunities for the development of new circular business models within tyre recycling industry.

\section{Materials and methods}

The main research methods are based on the integrative interdisciplinary approach (Fig. 1) combining literature review, the content and qualitative analysis, semi-structured in-depth interviews, case studies, quantitative statistical analyses and descriptive analyses. Forecast for tyre-recycling volumes were made, using the expert method and supplementing it with the time-series method. The expert method is based on the analysis of changes in the number of sold in the market and recycled EOL tyres and the projected direction of development of this ratio according to expert estimates. The time-series method is based on processing and analysis of statistical data of dynamics of changes in the number of tyres, using mathematical and statistical forecasting functions, selecting the most likely option, making the necessary adjustments according to the most credible scenario selected in the expert method. In addition, design-thinking methods contributed to conclusions on future opportunities of new tyre recycling business models. For the literature review, qualitative and content analyses of different secondary and primary literature sources are used, in particular, theoretical literature and academic publications, policy planning documents and other field professional information.

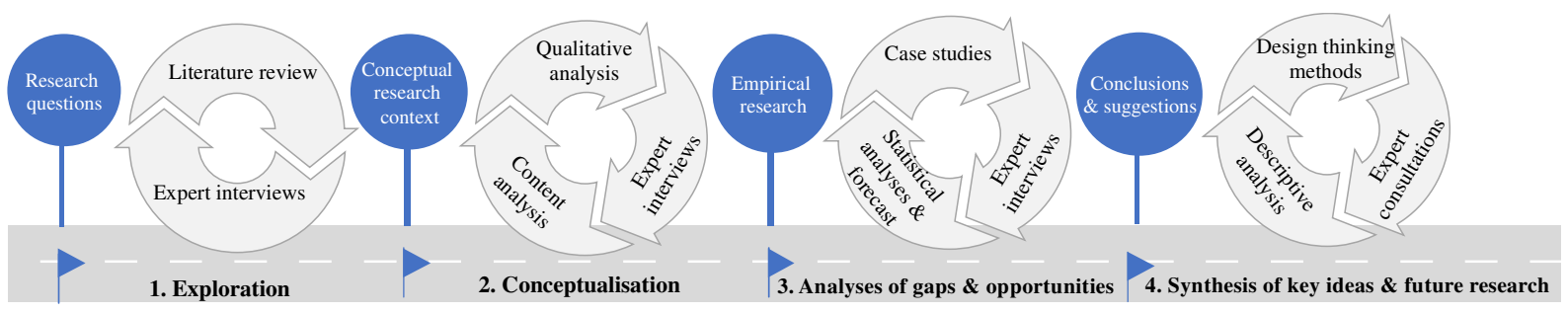

Fig. 1. Research conceptual approach and methods, source: created by the authors adapting from Geissdoerfer and co-workers [11]

For the case studies, we observed companies operating in the tyre recycling field in Latvia. In 2019, 8 companies are registered in this field with the permits to operate in the tyre-recycling field [12]. For further case studies of business models, 3 tyre recycling companies were selected: EDAUGAVA ltd.; VVV RECYCLING ltd.; R-TECHNOLOGY ltd. These companies actually operate in this field and have introduced new tyre recycling technologies [13]. The company ECO Baltia Vide Ltd. engaged in tyre recycling in the second half of 2019, so it was not included in the analysis of this study, as it is in the initiation stage within this business. However, we expect that ECO Baltia Vide Ltd. will continue to be an important player in the industry with significant competitive advantages in forthcoming years.

E-DAUGAVA ltd. has been operating in the industry since 2013 and is one of the oldest EOL tyre recycling companies in Latvia. The business model of E-DAUGAVA ltd. is focused on the tyre pyrolysis for fuel production. Full capacity of production of this company is $4500 t$ tyres [12; 13]. In its value proposition nor in the branding strategy, this company does not emphasize the sustainable development and environmental values. This company has established strong cooperation network with EOL tyre collection and management companies, but due to high accumulation of EOL tyre stocks, it has stopped accepting them.

VVV RECYCLING ltd. is currently one of the largest EOL tyre recycling companies in Latvia. The company uses mechanical tyre recycling for manufacturing rubber pellets of various fractions. Main revenue is generated from the sales of rubber pallets. Occasionally, it sells rubber mats in rather minor amount. This company also ensures the collection of EOL tyres, but these revenues are not substantial and just improve the efficiency of recycling costs. The company has an EOL tyre recycling capacity of 6000 tonnes per year, but currently it uses around 1000 tonnes [12; 13]. This company uses not only automobile, but also truck tyres. In the value proposition of this company the functionality of rubber pellets is stressed: for the manufacturing of tiles, surfacing rollers, seamless coating of playgrounds and sports fields, filler for sports equipment, asphaltic concrete modifiers, technical rubber products, car tyres, anti-corrosion mastic. In addition, their branding strategy emphasizes the values of sustainable development - closed loop for EOL tyre recycling. Main customers are 
manufacturers of rubber tiles and other related products in Latvia, Finland and Estonia. The collaboration network is formed by tyre suppliers form Latvia and Estonia.

R-TECHNOLOGY ltd. is the youngest one among the analysed companies, as it started tyre recycling in 2018. Full capacity of production of this company is $6000 \mathrm{t}$ tyres [12]. This company has implemented CBM with the greatest perspective compared to other tyre recycling companies. This is also evidenced by the financial performance of this company in recent years [13]. The company recycles EOL tyres for its own use. Further, on, from the obtained pellets rubber mats, rubber tiles and other rubber coatings are produced. The company has diversified the value proposition for various functionalities and various customer segments forming main revenue streams: 1) for home: terraces, verandas, balconies, outbuildings, garages, animal shelters, greenhouses, etc; 2) for sports: fitness facilities, outdoor fitness and sports grounds; 3 ) for children's playgrounds both indoors and outdoors. The value proposition has a particular emphasis on sustainability and environmental values: "Gentle for human, friendly for nature" [14]. Tyre suppliers and the Latvian Tyre Management Association form collaboration networks. Main customer segments are reached through DIY or construction retail chain stores in Latvia, Estonia and Lithuania.

As the good practice or benchmark of the tyre recycling CBMs we analysed the business model of the company Gelpro [15], which is the leading manufacturer of EOL tyre rubber products in the Czech Republic and successfully has adopted most of elements of CBMs.

\section{Results and discussion}

\section{Theoretical concepts, definitions and interpretations}

There are three types of recycling CBMs specified (Fig. 2). Down-cycling which allows utilisation of a waste or leftovers from the production providing materials with a lower value and quality, and up-cycling that is more challenging, but ensures manufacturing of products with higher value, quality and better functionality $[4 ; 5]$.

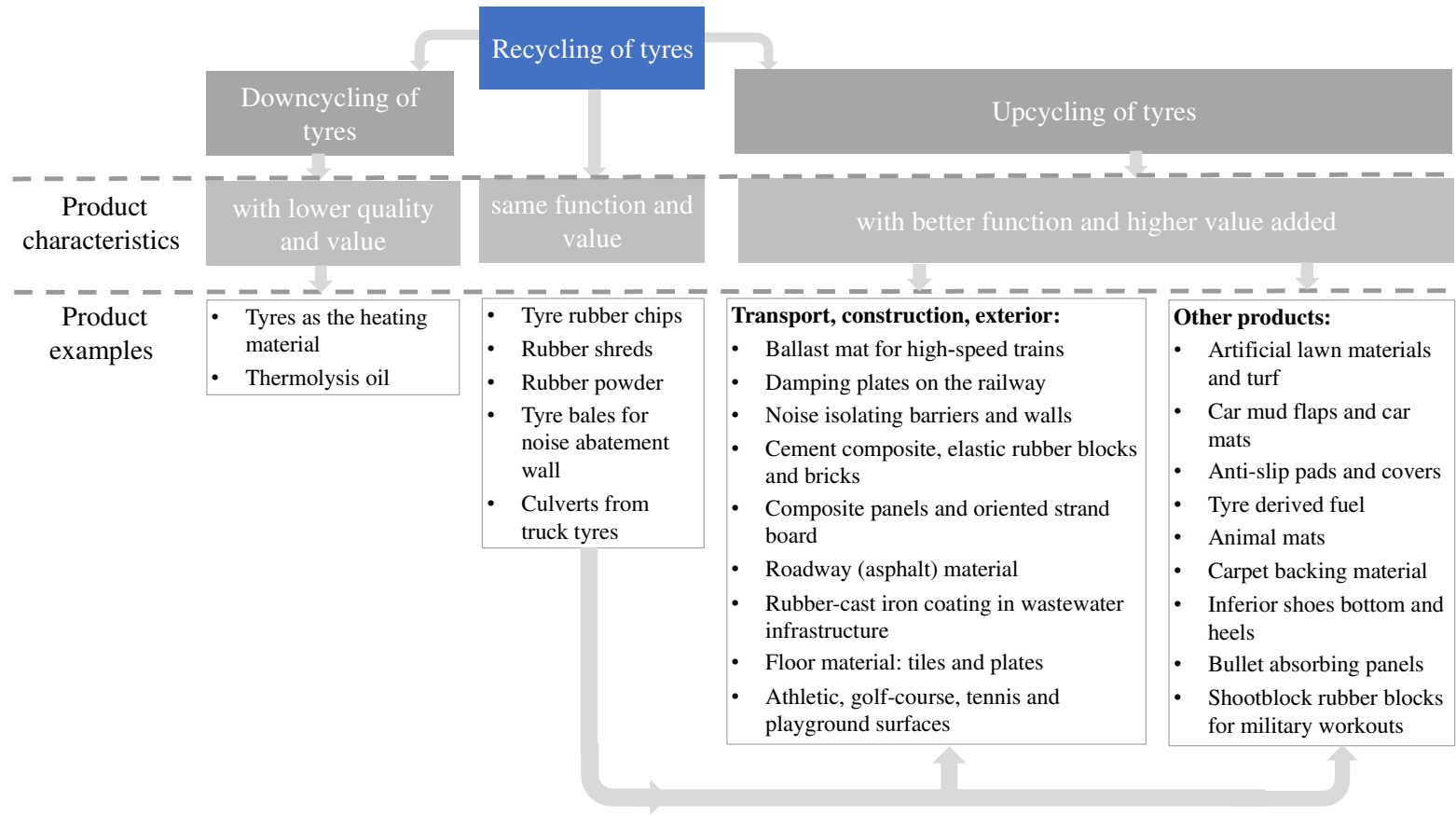

\section{Fig. 2. Types of recycling, product characteristics and examples}

Yet, many companies do not recognise the benefits provided by the circular business models and do not consider the waste as a useful resource, as often it requires large operating costs for development of innovative products or investments for adoption of new technologies. In addition, the dynamic capability of the entrepreneurs is significantly necessary to engage in and deal with the innovation process.

EOL tyres are a fairly inert and hard to recycle material that is not self-biodegradable and contains substances that cause pollution and pose a threat to the environment. Therefore, their recycling is 
necessary in order to convert the discarded EOL tyres into reusable raw materials or energy sources [16]. Companies must have a specific permit for the polluting business operations in order to carry out the tyre recycling process. Researchers [17] state that EOL tyres are one of the toughest, but outstandingly valuable polymeric waste, which may ensure from 1 ton of EOL tyres approximately $700 \mathrm{~kg}$ of rubber. This can further be manufactured into fuel products, rubber coverings, construction and other materials.

The tyre is a complex, multi-component engineering structure with several structural key elements. The tyres contain about 30 different materials, including rubber, silica, metal, textiles and other. The amount of particular materials contained varies depending on the type of tyre $[18 ; 19]$. There are different types of tyres (Fig. 3).

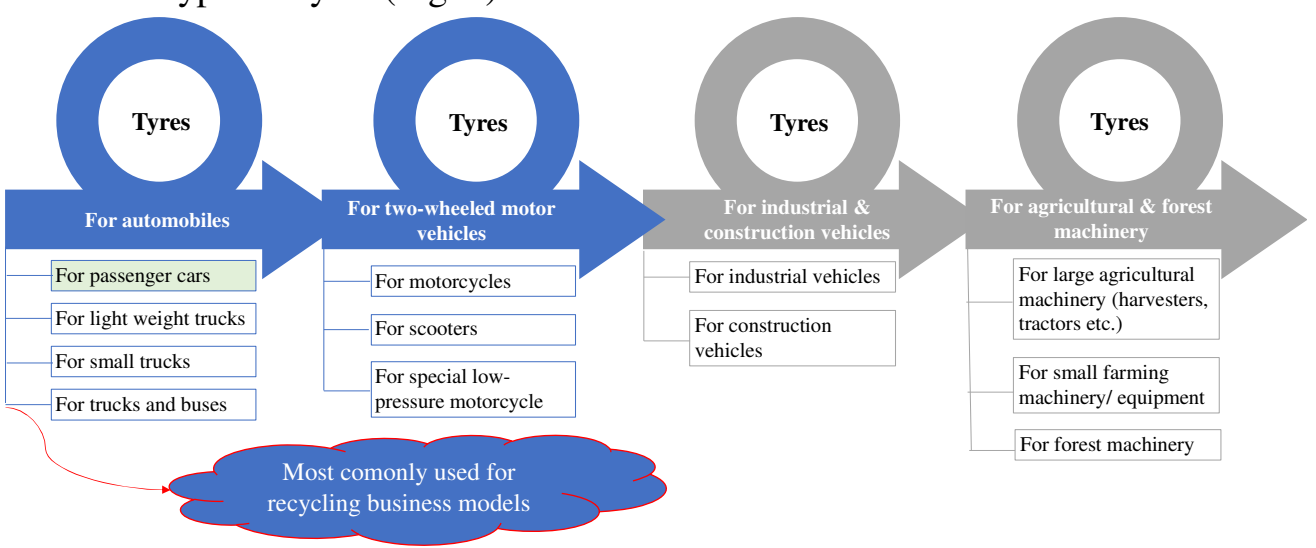

Fig. 3. Types of tyres, source: created by the authors based on $[18 ; 20]$

Due to the different composition of tyres, there are different ways of recycling them and therefore some types of tyres are more preferred than others. The most commonly used methods are pyrolysis, pelletizing and recycling of tyres into rubber chips. Tyre pyrolysis is a thermal degradation treatment method for rubber products, including, worn tyres. During pyrolysis, tyres are recycled at high temperatures, ultimately resulting in production of metal cords, carbon dust powders, and proline oil, which is used in fuel production $[17 ; 21]$.

Pelletizing of tyres includes shredding, granulating and atomizer. Shredding is the process of separating wire and meshes from a tyre and splitting them into pieces. The process takes place in a machine where the tyres are separated from the metal wires. Shredders of this machine are typically designed for a wide range of applications and can be utilised for recycling of other types of waste, such as pieces of plastic, pipes, films, textiles, cables, paper, wood and other organic materials. Granulating is used during the next step of the recycling process, where large pieces of tyre waste are cut into large granules, following the atomiser when the tyre pellet is processed into a fine rubber powder. Plastics, food, chemical and pharmaceutical waste can also be pulverized using similar technology $[3 ; 22]$.

Chip recycling is used to shred and chip both passenger and truck tyres. Special knife blades are used in the process to cut the tyre into fine irregular pieces [17]. Compared to pyrolysis, mechanical recycling is a solution that offers wider possibilities for further recycling of tyres, as the obtained raw materials can be used to make products with higher benefit. In order to have positive impacts on the sustainable development by innovative environment protection technologies, they should be adopted and commercialised by entrepreneurs [23], requiring dynamic managerial capabilities to seek for and develop new CBMs [24].

The recycling is one of the types of CBMs, which is focused on the treatment of EOL products and in such extending the resource value $[25 ; 26]$. Previously, researchers $[25 ; 27 ; 28]$ have explained that CBMs are characterized by 3 essential elements (Fig.4): circular value creation, circular value proposition and circular value capturing. When describing CBM and its innovation potential, researchers [29-32] frequently mention the importance of network and multi-stakeholder collaboration within the circular value chain. Therefore, we have identified the circular network as the fourth essential CBM element and we will use these four elements to characterize tyre-recycling CBMs. 


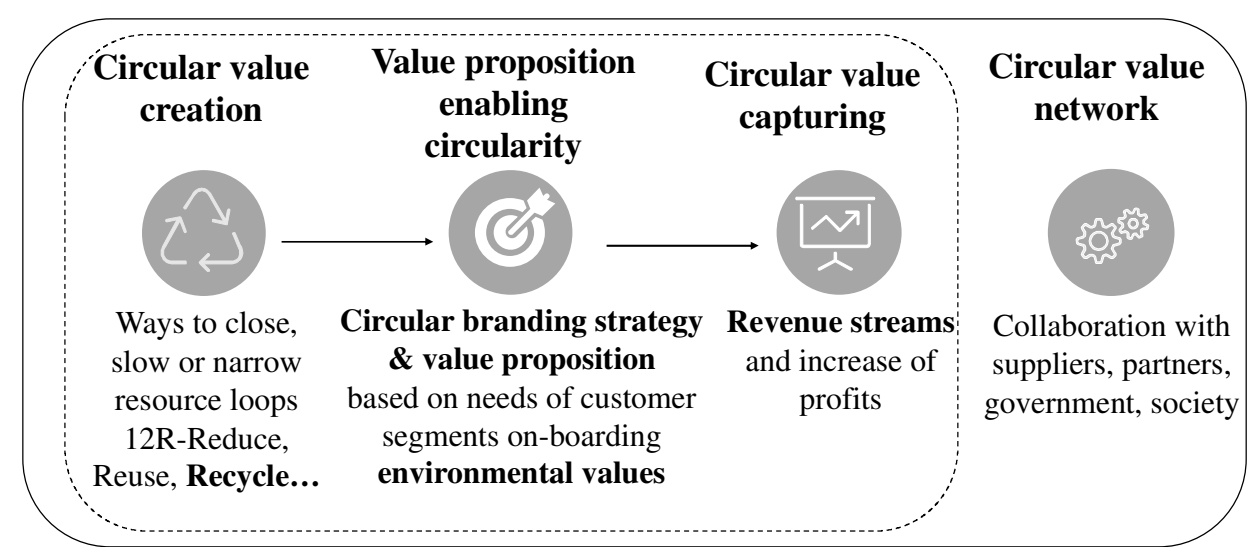

Fig. 4. Elements of circular business models

Adoption of new business models or business model innovations require changes in elements of existing business models, which may cover: 1) new ways of creating value, for instance by adopting new production technologies, 2) acquiring new customer segments, introducing new products or finding new solutions for customer needs in order to ensure new value proposition, and 3) introducing new revenue streams in order to increase profits and thus capturing the value $[25 ; 33]$.

\section{Tyre recycling situation in Latvia}

The roadmap (Fig. 6) shows the main economic cycles of tyres, recycling CBMs and key stakeholders in Latvia. The analyses of existing situation and consumer behaviour patterns in Latvia indicate signs of mostly dominant linear economy business models with mass production, consumption and waste generation of tyres in the $1^{\text {st }}$ economic cycle. While the $2^{\text {nd }}$ economic cycle with recycling business models bears the secondary role.

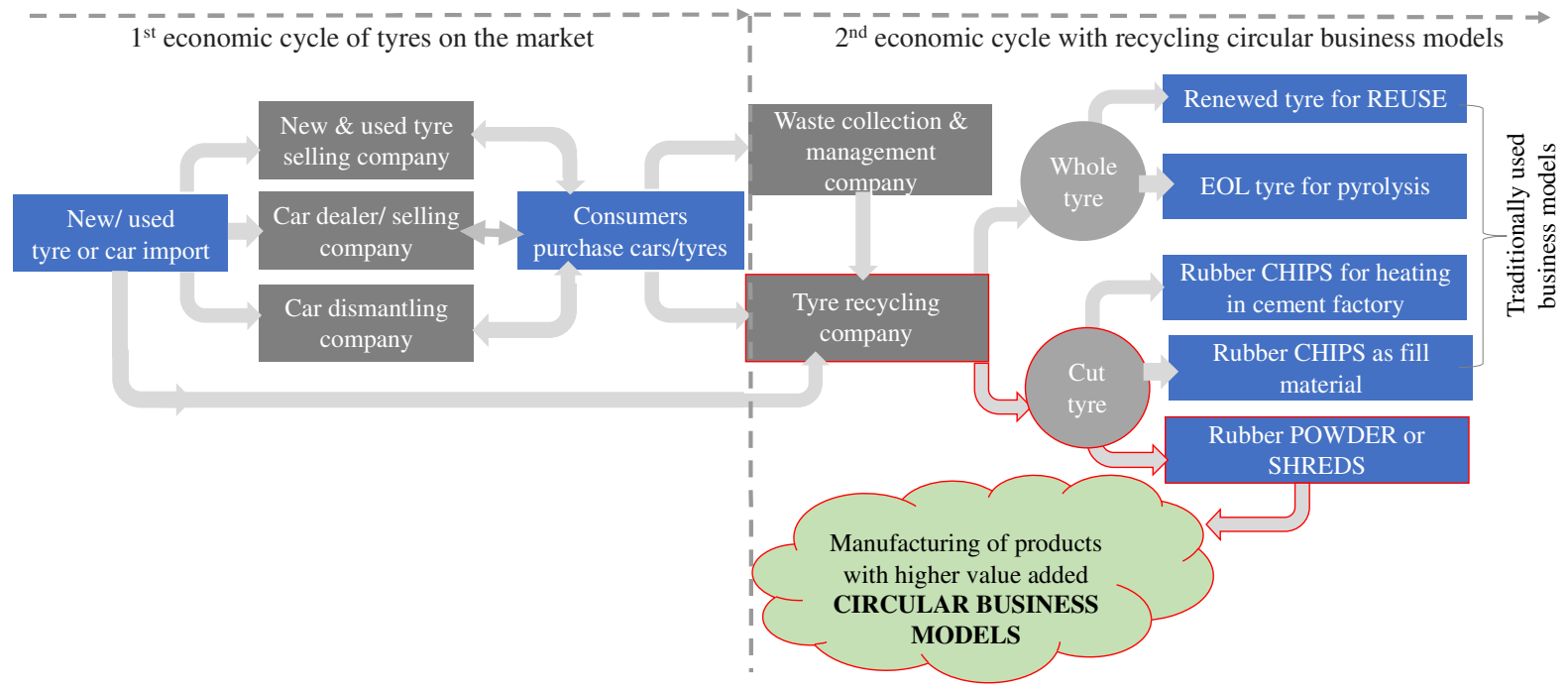

Fig. 5. Roadmap of tyre recycling towards new circular business models in Latvia

Latvia lacks environmentally driven and responsible waste recycling companies and this sector has tight entry barriers for companies willing to launch new recycling CBMs. Yet, an outstanding question remains regarding the collected and untreated number of tyres that increases annually. Although the proportion of recycled tyres increases gradually (Fig. 6), it is still significantly low comparing to other EU countries, ranking Latvia in the last place (Fig. 7).

In 2016, the State Environment Service (SES) suspended the tire-recycling permit of Riepu bloki ltd., one of former tyre recycling companies, which illegally had stored more than 1,000 tons of EOL tires instead of the 30 tons allowed and did not ensure the EOL tyre recycling in accordance with the requirements of regulatory enactments. The penalty fee of 12.9 million euros was imposed, which led Riepu bloki ltd. to the bankruptcy procedure [12]. This is the main reason of decrease in the number of recycled EOL tyres in 2016. Furthermore, this highlights the issue of the shadow economy presence 
within this sector that results in the illegal storage of EOL tyres and major fire accidents in tyre storage facilities.

EOL tyre recycling system in Latvia is not methodologically standardized from the government institutions. The supervisory and regulatory framework in Latvia should be improved regarding the tyre collection and waste management in order to encourage tyre waste management companies for proper collection of EOL tyres and reducing the shadow economy part within this sector. Otherwise, existing tyre recycling companies will have to import EOL tyres to ensure full production capacity.

The statistical data about the tyres sold and recycled is investigated occasionally and retrospectively. The lack of regular such statistical and monitoring data creates difficulties in developing appropriate policies and support mechanisms for introduction of new environment friendly recycling technologies and CBM. In Latvia, the number of recycled EOL tyres is still comparatively low, especially upcycling component manufacturing products with higher value added.

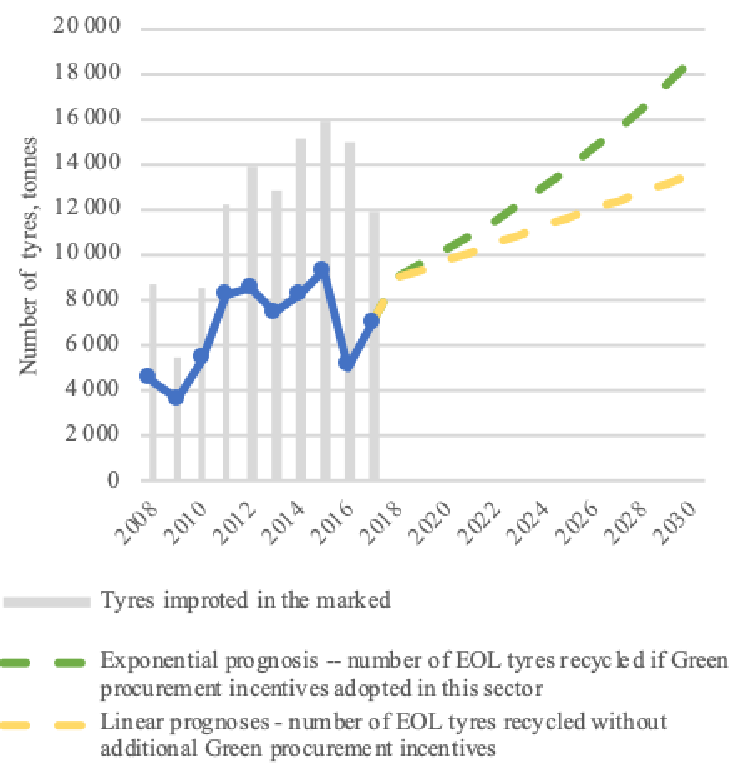

Fig. 6. Number of tyres sold and EOL tyres recycled in period $2008-2017 *$ and prognoses of it in Latvia for period 2018-2030, tons, source: created by the authors based on $[34 ; 35]$ data

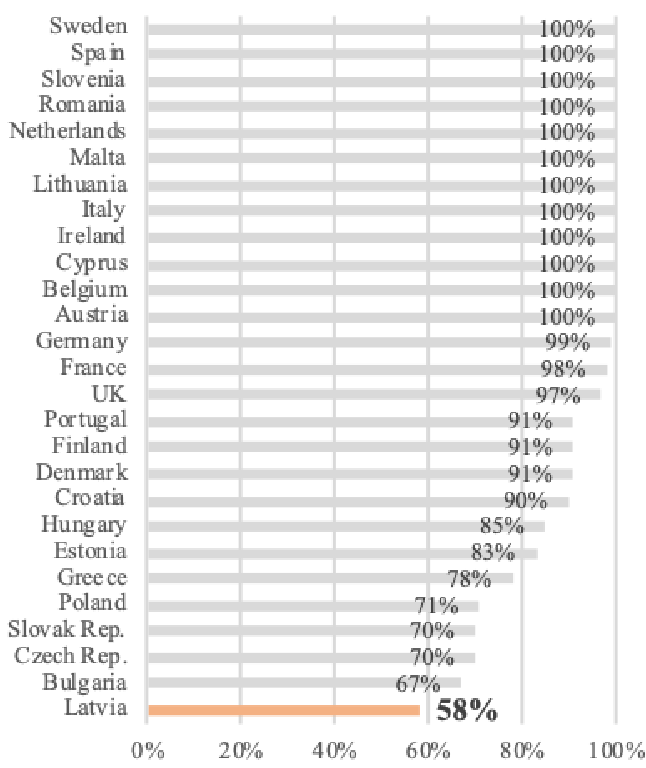

Fig. 7. Proportion of EOL tyres recycled from total number of tyres sold in EU countries in 2017**, source: created by the authors based on [36] data

* There are no annual data collected on EOL tyres in Latvia, therefore last available statistical data can be obtained from 2017

** 2017 statistical data are used in order to allow comparison data of Latvia with other EU countries

Wang with a co-author endorse the importance of the government in encouraging EOL tyre recycling by setting up policy planning and legislative framework, other social and cooperation mechanisms [37]. In this context the Green Public Procurement (GPP) is an essential government incentive that could encourage the transition of tyre-recycling and related business sectors towards the circularity, especially in the construction, military or transport sectors (see product examples in Fig. 2).

When evaluating existing tendencies of the public procurement, it is clear that public procurement in Latvia is part of the first and second stage of the social responsibility hierarchy [38], i.e. the tenderers prioritise the maximum profit (stage 1) while preparing the tender, and the contracting authority checks whether the tender meets all requirements specified in regulatory enactments (stage 2), including the standards and other obligations. This approach is ineffective and characterises short-term thinking, which in the long term does not effectively implement the socio-economic and legal interests of the society [39]. In the public sector, the emphasis should be placed on the quality of the subject matter of the procurement through the prism of costs arising from existence or nonexistence of a quality during the whole life cycle of the object. In this respect, with regard to the re-use 
of EOL tires, the GPP is not only a strategic direction for the Green Deal [2], but also an opportunity for the contracting authority to reduce costs of the product throughout its life cycle and in some cases after the end of the product's life it can be recycled again to produce new goods. In the context of sustainability, it does not even matter that this recycling is done according to interest of the same contracting authority, since the public procurement is not about saving one particular contracting authority's resources, but about ensuring the socio-economic and legal interests of the society as a whole, as well which characterises the purpose and quality of public procurement in general. Untapped potential is also the innovation procurement, through which the government could find solutions to escalating problems in housing yard coverage, by using recycled tyre products as cheaper and reusable, easy to dismantle material.

The prognoses (Fig. 6) show that adoption of the GPP regulatory framework regarding the use of EOL tyre recycled materials shall stimulate development of new recycling CBMs and thus increase the number of EOL tyres recycled. If such regulatory incentives are introduced by the government, in next 10 years Latvia may recycle more than $70 \%$ of annually imported tyres in such reaching other EU countries.

\section{Challenges and opportunities for new tyre recycling circular business models in Latvia}

Based on conceptualised main tyre-recycling CBM patterns in previous sections, this section describes the challenges and opportunities of Latvian tyre-recycling companies to realise new CBMs.

E-DAUGAVA ltd. is having major challenges in the tyre recycling business model applied. The fuel produced within the pyrolysis process must be certified before it is sold in the market. EDAUGAVA ltd. has not received such certification. Therefore, it has limited opportunities for development of the existing business model. In addition, the pyrolysis oil must be used within 1 year and, if not, it becomes environmentally hazardous waste, creating weakness of the existing business model. E-DAUGAVA ltd. currently is developing a new technology to produce fuel of a proper quality. Although the existing business model of E-Daugava ltd. is inefficient, the accumulated experience in this industry is a significant intangible resource.

VVV RECYCLING ltd. business model challenges are related to homogeneity of raw materials and undiversified production offer. The specific nature of the technology prevents the use of other types of tyres, which is a limiting factor. The company might offer rubber pellets for outdoor furniture production or start this type of production by themselves in order to diversify its product and value offer, as the company already has some experience in rubber covering production. Solutions for the production of outdoor furniture from rubber pellets have already been developed in the world and have not yet been introduced in Latvia. Such furniture can be used for private purposes, as well as for public sector, for instance, for rubber instead wooden benches.

The business model challenges of R-TECHNOLOGY ltd. are related to a relatively small sales network of retail stores and unused processing capacity. It is necessary to geographically expand the sales market and look for wider sales opportunities in the business-to-business (B2B) segment that can use rubber pellets for manufacturing of other products or in the construction sector. The company shall expand its business-to-government (B2G) segment by offering products, for example to municipalities that are interested in the construction of playgrounds. The company can implement CBM, based on product-service systems [40] by offering rubber cover for rent and after the lease expires, ensuring the cover is returned and recycling. There is a potential opportunity for this company to develop its brand as a valuable intangible resource, especially emphasizing the use of tyre recycling technologies.

Table 1 categorises the main elements of tyre recycling CBM and assesses the opportunities of the analysed tyre recycling companies for the transition to new CBMs.

The largest part of the tyre recycling companies focuses their business models on the downcycling or recycling manufacturing products with a lower or the same value, quality and limited functionality. Most often EOL tyres are used as a source of energy, which is confirmed also by other researchers [3]. Such companies as R-TECHNOLOGY ltd. shall act as the role model for other local companies to encourage and engage more manufacturers in this field. This will promote an interest of wider customer segments to purchase and use tyre-recycled rubber products of local companies instead of importing them from abroad. 
There is a belief among local consumers that the products manufactured in Latvia are not yet of the same quality as foreign analogue, because the tyre processing industry and the technologies used in Latvia are in an early development stage. Educating potential customers especially in B2B or B2G sectors on the quality and functionally of tyre-recycled rubber products may open additional opportunities to diversify customer segments and expand the market share in Latvia.

Table 1

\section{Existing and potential opportunities of tyre recycling companies} for the transition to new CBMs

\begin{tabular}{|c|c|c|c|c|}
\hline \multirow{2}{*}{$\begin{array}{l}\text { Elements } \\
\text { of CBM }\end{array}$} & \multirow{2}{*}{$\begin{array}{l}\text { Options of CBM } \\
\text { elements }\end{array}$} & \multicolumn{3}{|c|}{$\begin{array}{c}\text { Level of Opportunities } \\
\text { (“-" no opportunities, X- in leser extent, XX - in greater extent) }\end{array}$} \\
\hline & & E-DAUGAVA & $\begin{array}{c}\text { VVV } \\
\text { RECYCLING }\end{array}$ & R-TECHNOLOGY \\
\hline \multirow{3}{*}{$\begin{array}{l}\text { Value } \\
\text { creation }\end{array}$} & Up-cycling & - & $\mathrm{X}$ & $\mathrm{XX}$ \\
\hline & Re-cycling & - & $\mathrm{XX}$ & - \\
\hline & Down-cycling & $\mathrm{XX}$ & - & - \\
\hline \multirow{5}{*}{$\begin{array}{l}\text { Value } \\
\text { propositio } \\
\mathrm{n}(\mathrm{VP})\end{array}$} & $\begin{array}{l}\text { Circular values in VP } \\
\text { and branding strategy }\end{array}$ & - & $\mathrm{X}$ & $\mathrm{XX}$ \\
\hline & $\begin{array}{l}\text { Higher value added } \\
\text { (HVA) products for } \\
\text { construction and } \\
\text { exterior sectors }\end{array}$ & - & $X$ & $\mathrm{XX}$ \\
\hline & $\begin{array}{l}\text { HVA products for } \\
\text { transport and car } \\
\text { sectors }\end{array}$ & Xpo & $\mathrm{X}$ & $\mathrm{XX}$ \\
\hline & $\begin{array}{c}\text { HVA products for } \\
\text { other sectors (military, } \\
\text { agro, etc.) }\end{array}$ & - & $X$ & $\mathrm{XX}$ \\
\hline & $\begin{array}{l}\text { EOL tyre waste } \\
\text { collection services }\end{array}$ & $\mathrm{XX}$ & $\mathrm{XX}$ & - \\
\hline \multirow{2}{*}{$\begin{array}{l}\text { Value } \\
\text { capturing }\end{array}$} & $\begin{array}{l}\text { Various and diversified } \\
\text { customer segments }\end{array}$ & Xpo & XXpo & $\mathrm{XX}$ \\
\hline & $\begin{array}{c}\text { Various and diversified } \\
\text { revenue streams }\end{array}$ & Xpo & XXpo & $\mathrm{XX}$ \\
\hline \multirow{4}{*}{$\begin{array}{l}\text { Circular } \\
\text { value } \\
\text { network }\end{array}$} & $\begin{array}{c}\text { Facilitating } \\
\text { collaboration within } \\
\text { tyre recycling sector }\end{array}$ & XX & $X$ & $\mathrm{XX}$ \\
\hline & $\begin{array}{l}\text { Customer and supplier } \\
\text { education }\end{array}$ & XXpo & $\mathrm{X}$ & XX \\
\hline & $\begin{array}{l}\text { Sharing of expertise in } \\
\text { recycling technologies }\end{array}$ & $\mathrm{XX}$ & $X$ & $\mathrm{XX}$ \\
\hline & $\begin{array}{c}\text { Engaging societal } \\
\text { involvement in tyre } \\
\text { recycling }\end{array}$ & Xpo & Xpo & - \\
\hline
\end{tabular}

Xpo - company does not obtain, but has a strong potential to acquire this opportunity with comparatively minimal efforts

Source: created by the authors adapting from Ludeke-Freund and co-authors [6]

From the perspective of new CMB, the use of pyrolysis for production of fuel from pyrolysis oil has not been successfully introduced in Latvia. The lack of proper certification to be used and sold this fuel in the market is one of the issues to be solved in order to maximise new CBM opportunities provided. The use of pyrolysis in Europe is decreasing; however, there are new incentives, especially in the northern EU, to investigate and launch new opportunities for using pyrolysis oil for manufacturing tyre-derived fuel and other products. This will open new opportunities for companies using pyrolysis technology for tyre-recycling.

In Latvia, for recycling and, in particular, upcycling CBMs, companies mostly prefer to use tyres of passenger cars. Other types of tyres are left for landfills, sales as "second-hand" tyres, used as the 
heating material and for other reuse purposes. This indicates unused potential to design and develop new technologies and new circular business models for recycling of other types of tyres. Some of existing tyre recycling companies in Latvia shall import EOL tyres as lack sufficient supplies in the domestic market. This highlights the importance of the need to widen opportunities for recycling of various types of tyres.

There is a potential opportunity of developing new CBM in collaboration with oriented strand board (OSB) manufacturing companies. OSB is becoming increasingly popular in the construction industry as a load-bearing and reinforcing building element in construction of walls, floors and roofs. The material's popularity can be explained by its properties - OSB is a flexible, but durable plate with stable dimensions, relatively waterproof and easy to process [41]. Addition of rubber could increase water resistance of the plates by at least $10 \%$ [42]. Moreover, still unused potential of developing new CBMs and innovative products with higher value added can be found within the military industry and in various agro-business related sectors.

As evidenced by the results of the analysis summarized in the matrix model (Fig.8), it is possible to identify opportunities for tyre- recycling companies to adopt new CBMs. Although, there is a different advancement level of tyre recycling companies to use opportunities identified. In general, overall tyre-recycling market varies between emerging and promising level of opportunities to introduce new CBMs with some exceptional cases. R-TECHNOLOGY ltd. demonstrates outstanding possibilities in this sector. In addition, we expect that ECO Baltia Vide ltd. will reach outstanding positions because of strongly developed various CBM portfolios of waste recycling within the holding.

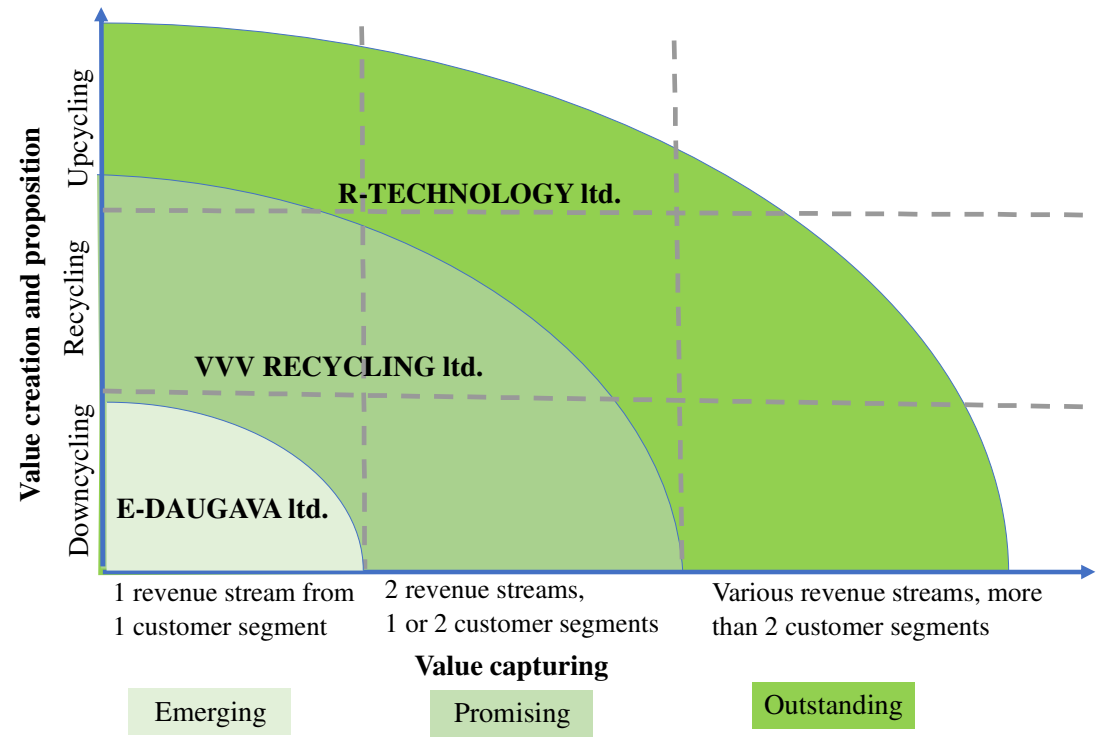

Fig. 8. Matrix of the level of adoption of new circular business models in tyre recycling companies in Latvia

\section{Conclusions}

1. There is no established sufficient supervision and monitoring of the EOL tires from selling, receiving to disposing or recycling. There are no regular, annual data collected on the number of EOL tyres recycled in Latvia. Improving the monitoring and regulation of the EOL tyre waste management is essential for the tyre recycling industry, as there is currently no incentive for waste management companies to supply EOL tyres for recycling.

2. In Latvia, the restructuring of business models towards the circularity shall be promoted. The implementation of GPP requirements is very important in this respect to increase the sales and motivate tyre-recycling companies to adopt new CBMs with innovative technologies and various rubber products.

3. In tyre-recycling companies, particular focus should be paid on the development of new upcycling-oriented circular business models. This will provide new business perspectives for 
producing new products with higher value added. In addition, it will allow utilisation of larger amounts of EOL tyres more effectively from economic and environmental aspects.

4. Tyre-recycling companies have to re-design their branding strategies and the value proposition with greater extent emphasizing the sustainability and environmental values.

5. The markets of Latvia and other Baltic countries are limited and comparatively small to accommodate the products of all EOL tyres. Therefore, the acquisition of new external markets and various customer segments is necessary and crucially important for appropriate value capturing.

6. This research reveals several aspects that should be investigated by future researches, more detailed financial and non-financial benefits of tyre recycling companies to adopt new CBMs, the necessary market capacity to ensure sufficient value capturing and return on investments.

7. The future research work may identify the benchmark criteria and patterns of central European countries of tyre recycling CBMs to be adopted in eastern European countries with smaller proportion of EOL tyres recycled.

8. Investigation of customer or user perspective of tyre derived rubber products may help in further development of more focused CBMs and, in particular, value propositions.

9. Publications still lack more detailed context analyses on the circular value network and role of various stakeholders encompassing CBMs in the tyre recycling sector, the future research may address this gap.

\section{Acknowledgements}

Many thanks for the opportunity to conduct and publish this research to BA School of Business and Finance (Latvia) with the research project "Management of Circular Business Models and Projects within Economy of Latvia", and Liepaja University (Latvia) with the project "Promotion of research, innovation and international cooperation in science at Liepaja University (No 1.1.1.5/18/1/018)".

\section{References}

[1] ETRMA. Roadmap New Circular Economy Action Plan, ETRMA Contribution. European Tyre\&Rubber Manufacturers'Association. [online] [05.02.2020]. Available at: www.etrma.org/wp-content/uploads/2020/01/20200120-Roadmap-CE-Action-Plan-ETRMAfinal.pdf.

[2] European Comission. Communication from the Commission to the European Parliament, the Council, the European Economic and Social Committee and the Committee of the Regions. The European Green Deal. Brussels, 11.12.2019.

[3] Urbans M., Vilcane I. and Malahova J. Assessment of Technogenic Risks in Recovering Company for Worn Tyres. Proceedings of 18th International Scientific Conference "Engineering for Rural Development” Vol 18, ISSN 1691 - 5976, 2019, pp.1616-1622.

[4] Uvarova I., Atstaja Dz. Korpa V. "Challenges of the Introduction of Circular Business Models Within Rural SMEs of EU”, International Journal of Economic Sciences, VOL IX, 2020, No. 2.

[5] EMF. Towards the Circular Economy: Economic and Business Rationale for an Accelerated Transition. Ellen MacArthur Foundation, 2012, No. 1

[6] Ludeke-Freund F., Gold S., Bocken N. M. A Review and Typology of Circular Economy Business Model Patterns. Journal of Industrial Ecology, 23(1), 2019, pp. 36-61.

[7] Kirchherr J., Reike D., Hekkert M. Conceptualizing the Circular Economy: An Analysis of 114 Definitions. Resources, Conservation and Recycling, 127, 2017, pp. 221-232.

[8] Spengler T., Puchert H., Penkuhn T., Rentz O. Environmental Integrated Production and Recycling Management. European Journal of Operational Research, 97(2), 1997, pp. 308-326.

[9] Scheirs, J. Polymer Recycling: Science, Technology and Applications. New York: Wiley, 1998, Vol. 132.

[10] Laresgoiti M. F., de Marco I., Torres A., Caballero B., Cabrero M. A., Chomón M. J. Chromatographic Analysis of the Gases Obtained in Tyre Pyrolysis. Journal of Analytical and Applied Pyrolysis, 55(1), 2000, pp. 43-54. 
[11] Geissdoerfer M., Bocken N. M., Hultink E. J. Design Thinking to Enhance the Sustainable Business Modelling Process-A Workshop Based on a Value Mapping Process. Journal of Cleaner Production, 135, 2016, pp. 1218-1232.

[12] State Environmental Service of Republic of Latvia. [online] [03.12.2019]. Available at: www.vvd.gov.lv.

[13] Uvarova I., Atstaja Dz., Korpa V. Erdmanis M. "Financial Viability of Circular Business Models in Tyre Recycling Industry in Latvia", Proceedings of the 2020 International Conference "Economic Science for Rural Development" Jelgava, LLU ESAF, 2020.

[14] CowerPower. R-TECHNOLOGY - Par mums. (R-TECHNOLOGY- About us). [online] [15.02.2020]. Available at: www.cover-power.com

[15] Gelpo ltd.. [online] [03.03.2020]. Available at: https://www.gelpo.cz/home.

[16] LRAA, Par atpazīstamības zīmi "Riepa ar rītdienu" (About the brand, tyre of future). [online] [13.01.2020]. Available at: https://lraa.lv/par-lraa-atpazistamibas-zimi-riepa-arritdienu/?fbclid=IwAR2RPSimKWyCxSFQzCEQSo_dtUWnpjf26sT5Z6Sa9psrjaj51SilSzq6I_E.

[17] Gorbunov M., Kravchenko A., Gerlici J., Kravchenko K., Hauser V., Lack T. Processing and Recycling of Rubber and Oil Wastes Into Hydrocarbon Fuel By Method Of Physico-Chemical Activation. In Proceedings of the 18th International Scientific Conference" Engineering for Rural Development", Jelgava, Latvia, 2019, pp. 988-994

[18] Kaltire. What's attire made of? Tire ingredients for the perfect rubber recipe. [online] [12.12.2019]. Available at: https://info.kaltire.com/whats-tire-made-tire-ingredients-perfectrubber-recipe/.

[19] Pandya M., Patel R. N., Amarnath S. K. P. Determination of Time Delay and Rate of Temperature Change During Tyre Curing (Vulcanizing) Cycle. Procedia Engineering, 51, 2013, pp.828-833.

[20] Nakao Y., Yamamoto K. Waste Tire Recycle and Its Collection System. Nippon Steel Technical Report No 86, JIS, 500, 2002, 4202.

[21]iPEC "Riepu pirolīze. 5 fakti par gumijas pārstrādāšanu" (Pyrolysis of tires. 5 facts about recycling rubber), [online] [20.11.2019]. Available at: https://i-pec.lv/lv/news/riepu-pirolize-5fakti-par-gumijas-parstradasanu.

[22] Wealthy Waste "Rubber Powder from Waste Tyres: An Approach to Tyre Recycling". [online] [13.01.2020]. Available at: www.wealthywaste.com/rubber-powder-from-waste-tyres-anapproach-to-tyre-recycling.

[23] Tambovceva T., Tereshina M., Samarina V. Green Innovations in Regional Economy. Proceedings of 18th International Scientific Conference "Engineering for Rural Development" Vol 18, ISSN 1691 - 597, 2019, pp.1832-1839.

[24] Uvarova I., Vitola A. Innovation Challenges and Opportunities in European Rural SMEs. Public policy and administration, 18(1), 2019, pp. 152-166.

[25] Nußholz J. L. Circular Business Models: Defining a Concept and Framing an Emerging Research Field. Sustainability, 9(10), 2017, 1810.

[26] Bocken N. M., De Pauw I., Bakker C., van der Grinten B. Product Design and Business Model Strategies for a Circular Economy. Journal of Industrial and Production Engineering, 33(5), 2016, pp. 308-320.

[27] Bocken N. M., Schuit C. S., Kraaijenhagen C. Experimenting with a Circular Business Model: Lessons from Eight Cases. Environmental Innovation and Societal Transitions, 28, 2018, pp. 7995.

[28] Urbinati A., Chiaroni D., Chiesa V. Towards a New Taxonomy of Circular Economy Business Models. Journal of Cleaner Production, 168, 2017, pp. 487-498.

[29] Kennedy S., Bocken N. Innovating Business Models for Sustainability: An Essential Practice for Responsible Managers. The Research Handbook of Responsible Management. Cheltenham: Edward Elgar, 2020.

[30] Balaman S. Y., Wright D. G., Scott J., Matopoulos A. Network Design and Technology Management for Waste to Energy Production: An Integrated Optimization Framework under the Principles of Circular Economy. Energy, 143, 2018, pp. 911-933.

[31] Antikainen M., Valkokari K. A Framework for Sustainable Circular Business Model Innovation. Technology Innovation Management Review, 2016, 6(7). 
[32]Rohrbeck R., Konnertz L., Knab S. Collaborative Business Modelling for Systemic and Sustainability Innovations. International Journal of Technology Management, 63(1/2), 2013, pp.423.

[33] Uvarova I., Atstaja D., Vitola A. Circular Economy Driven Innovations Within Business Models of Rural SMEs. In Proceedings of the International Scientific Conference. Volume VI, 2019, p. $520-530$.

[34] Gatway\&Partners. Labāko prakses piemēru, ts.k. komercsektora pieredzes, Latvijā un ārvalstīs izvērtěšana un apkopošana zạ̣ā iepirkuma jomā. VARAM (Best practices in the field of Green procurement, incl. evaluating and summarising experience of the private sector in Latvia and abroad. MEPRD), 2018.

[35]LRAA, Industry Data. Annually 30\% of Imported Tyres in the Market are not Collected and Recycled. [online] [13.01.2020]. Available at: http://lraa.lv/en/industry/.

[36] European Tyre\&Rubber Manufacturers'Association. ELT Management Figures -Europe-2017 Status. European Tyre\&Rubber Manufacturers'Association. [online] [05.02.2020]. Available at:www.etrma.org/wp-content/uploads/2019/11/ELT-Management-Figures-2017-vf.xlsx.pdf.

[37] Wang H. Z., Xu H., Xuan X. J. Review of Waste Tire ReuseRecycling in China-Current Situation, Problems and Countermeasures. Advances in Natural Science, 2(1), 2010, pp. 31-39.

[38] Carrol B.A. Three-Dimensional Conceptual Model of Corporate Social performance. Academy of Management Review, vol. 4, 1979, pp. 497-505.

[39] Avena L. Social Responsibility as a Component of Tender Assessment within the Public Procurement Process. Proceedings of the 61st International Scientific Conference of Daugavpils University. Part B "Social Sciences", 2019, pp.228-233

[40] Yang M., Evans S. Product-Service System Business Model Archetypes and Sustainability. Journal of Cleaner Production, 220, 2019, pp. 1156-1166.

[41] Fatjanovs S. Orientēto skaidu plātṇu izmantošana. (The use of oriented strand boards). [online] [16.12.2019]. Available at: https://abc.lv/raksts/osb_platnes.

[42] Ayrilmis N., Buyuksari U., Avci E. Utilization of waste tire rubber in manufacture of oriented strandboard, Waste Management, Volume 29, Issue 9, 2009, pp.2557 